\title{
Clinical Manifestations in Carriers of X-Linked Chronic Granulomatous Disease in Mexico
}

López-Hernández I ${ }^{1}$, Guzmán-Martínez $\mathrm{MN}^{1}$, Medina-Vera $\mathrm{I}^{2}$, Yamazaki-Nakashimada $\mathrm{MA}^{3}$, Saracho-Weber F${ }^{4}$, GámezGonzález LB ${ }^{4}$, Saez-de-Ocariz $\mathrm{M}^{5}$, Espinosa-Padilla $\mathrm{SE}^{1}$, Blancas-Galicia $\mathrm{L}^{1}$

${ }^{1}$ Immunodeficiencies Research Unit, National Pediatrics Institute, Mexico City, Mexico

${ }^{2}$ Department of Research Methodology, National Pediatrics Institute, Mexico City, Mexico

${ }^{3}$ Department of Clinical Immunology, National Pediatrics Institute, Mexico City, Mexico

${ }^{4}$ Clinical Immunology Department, Chihuahua Children Hospital, Chihuahua, Mexico

${ }^{5}$ Department of Dermatology, National Pediatrics Institute, Mexico City, Mexico

J Investig Allergol Clin Immunol 2019; Vol. 29(2): 134-136 doi: $10.18176 /$ jiaci.0343

Key words: Chronic granulomatous disease. X-linked carriers. Dihydrorhodamine. NADPH-oxidase. Discoid lupus.

Palabras clave: Enfermedad granulomatosa crónica. Portadoras ligadas a cromosoma X. Dihidrorodamina. NADPH oxidasa. Lupus discoide.

Chronic granulomatous disease (CGD) is characterized by defects in NADPH oxidase, causing phagocytes to improperly clear invading pathogens. Owing to lyonization, X-linked CGD carriers (XL-CGD) have a dual phagocyte population, with $20 \%$ to $80 \%$ functioning phagocytes. Neutrophils with inactivation of the mutated $\mathrm{X}$ chromosome in the $C Y B B$ gene have a normal respiratory burst, whereas neutrophils with inactivation of the normal $\mathrm{X}$ chromosome have a CGD phenotype [1-3].

XL-CGD carriers exhibit a variety of autoimmune manifestations, mainly lupus-like signs and symptoms [3-5]. Skin diseases include recurrent photosensitive rash, folliculitis, postadolescent acne, eczema, and oral aphthous ulcers [1]. Gastrointestinal manifestations include abdominal pain, intermittent diarrhea, rectal bleeding, and chronic inflammatory bowel disease [6]. Recurrent infections characteristic of CGD include recurrent skin abscesses, pneumonia, hidradenitis suppurativa, and liver abscesses [2,5]. Other symptoms are chorioretinitis and fatigue [7]. All of these symptoms have an impact on quality of life.

No studies have documented the symptoms presented by XL-CGD carriers in Latin America. The aims of this study were to describe the main signs and symptoms of Mexican XL-CGD carriers and to correlate the percentage of neutrophils with normal production of hydrogen peroxide $\left(\mathrm{H}_{2} \mathrm{O}_{2}{ }^{+}\right)$and various clinical variables.

Sixty-five XL-CGD carriers diagnosed from 2011 to 2018 were invited to participate, although not all accepted the invitation. Informed consent and/or assent were obtained from 
all participants. Carriers were shown to have a dual phagocytic cell population, as confirmed by the 1,2,3-dihydrorodamine assay. A detailed health survey was administered to 42 female carriers from 29 kindreds to detect the presence of data suggestive of disease. The median age of the group was 39.2 years (range, 7-73 years). The relationship between the carriers and the CGD patients was as follows: 29 mothers, 9 grandmothers, 2 sisters, and 2 aunts. The mean (SD) percentage for $\mathrm{H}_{2} \mathrm{O}_{2}{ }^{+}$neutrophils was $47.9 \%$ (20.3\%). The clinical manifestations are shown in the Table.

To determine whether a lower percentage of unaffected neutrophils $\left(\mathrm{H}_{2} \mathrm{O}_{2}{ }^{+}\right)$was associated with the presence of the different clinical variables, a correlation was made between the different manifestations and 2 groups of carriers $\left(\mathrm{H}_{2} \mathrm{O}_{2}{ }^{+}\right.$ neutrophils $\leq 40 \%$ and $\mathrm{H}_{2} \mathrm{O}_{2}{ }^{+}$neutrophils $>40 \%$ ). The cut-off point was set arbitrarily according to the distribution of the sample.

Aphthous stomatitis and gingivitis were the only signs that were found to be statistically significant (Table). The remaining clinical variables were also analyzed; however, we did not find a statistically significant difference between the 2 groups.

The clinical manifestations reported in this cohort were all present, regardless of whether they had previously been associated with XL-CGD carriers [1-5]. As in other series, dermatological symptoms were reported in almost half of the participants. We also found a girl with ectodermal dysplasia, which had not been previously associated with having XL-

Table. Clinical Manifestations in $42 \mathrm{XL}-\mathrm{CGD}$ Carriers

\begin{tabular}{|c|c|c|c|c|}
\hline Manifestation & $\begin{array}{c}\text { No. }(\%) \\
N=42\end{array}$ & $\begin{array}{c}\mathrm{H}_{2} \mathrm{O}_{2}^{-} \leq 40 \% \\
\mathrm{~N}=17\end{array}$ & $\begin{array}{c}\mathrm{H}_{2} \mathrm{O}_{2}^{+}>40 \% \\
\mathrm{~N}=25\end{array}$ & P Value $^{\mathrm{a}}$ \\
\hline \multicolumn{5}{|l|}{ Gastrointestinal manifestations } \\
\hline Constipation & $13(31)$ & $6(35)$ & $7(28)$ & .616 \\
\hline Intermittent noninfectious diarrhea & $9(21)$ & $2(12)$ & $7(28)$ & .192 \\
\hline Gastroesophageal reflux & $6(14)$ & $3(18)$ & $3(12)$ & .466 \\
\hline \multicolumn{5}{|l|}{ Dermatologic manifestations } \\
\hline Photosensitivity & $17(40)$ & $7(41)$ & $10(40)$ & .939 \\
\hline Postadolescence acne & $10(24)$ & $5(30)$ & $5(20)$ & .482 \\
\hline Recurrent cutaneous abscesses & $3(7)$ & $1(6)$ & $2(8)$ & .645 \\
\hline Ectodermal dysplasia & $1(2)$ & $0(0)$ & $1(4)$ & $*$ \\
\hline Rosacea & $1(2)$ & $1(6)$ & $0(0)$ & $*$ \\
\hline \multicolumn{5}{|l|}{ Autoimmune manifestations } \\
\hline Arthralgia & $18(43)$ & $5(30)$ & $13(52)$ & .147 \\
\hline Aphthous stomatitis & $15(36)$ & $11(65)$ & $4(16)$ & .002 \\
\hline Fatigue & $10(24)$ & $4(24)$ & $6(24)$ & .627 \\
\hline Polyarthritis & $7(17)$ & $1(6)$ & $6(24)$ & .129 \\
\hline Autoimmune hemolytic anemia & $1(2)$ & $0(0)$ & $1(4)$ & $*$ \\
\hline Juvenile idiopathic arthritis & $1(2)$ & $0(0)$ & $1(4)$ & $*$ \\
\hline Sjögren syndrome & $1(2)$ & $1(6)$ & $0(0)$ & $*$ \\
\hline Discoid lupus & $1(2)$ & $0(0)$ & $1(4)$ & * \\
\hline Rheumatoid arthritis & $1(2)$ & $0(0)$ & $1(4)$ & $*$ \\
\hline \multicolumn{5}{|l|}{ Infections } \\
\hline Recurrent vaginal infections & $12(29)$ & $7(41)$ & $5(20)$ & .136 \\
\hline Recurrent lower urinary tract infections & $12(29)$ & $7(41)$ & $5(20)$ & .136 \\
\hline Recurrent rhinopharyngitis & $8(19)$ & $4(24)$ & $4(16)$ & .411 \\
\hline Pharyngotonsillitis & $6(14)$ & $2(12)$ & $4(16)$ & .534 \\
\hline Pneumonia & $3(7)$ & $2(12)$ & $1(4)$ & .355 \\
\hline Allergic rhinitis & $2(5)$ & $2(12)$ & $0(0)$ & .158 \\
\hline Liver abscess & $1(2)$ & $1(6)$ & $0(0)$ & $*$ \\
\hline Hidradenitis suppurativa & $1(2)$ & $1(6)$ & $0(0)$ & * \\
\hline \multicolumn{5}{|l|}{ Other manifestations } \\
\hline Miscarriage & $14(33)$ & $4(24)$ & $10(40)$ & .209 \\
\hline Gingivitis & $14(33)$ & $9(53)$ & $5(20)$ & .026 \\
\hline Chronic headache & $13(31)$ & $4(24)$ & $9(36)$ & .305 \\
\hline Transient blurred vision & $8(19)$ & $6(24)$ & $2(12)$ & .282 \\
\hline Insomnia & $7(17)$ & $3(18)$ & $4(16)$ & .603 \\
\hline Depression & $5(12)$ & $3(18)$ & $2(8)$ & .317 \\
\hline Hypothyroidism & $3(7)$ & $3(12)$ & $0(0)$ & .200 \\
\hline
\end{tabular}

Abbreviations: XL-CGD, X-linked chronic granulomatous disease.

aifferences in percentages for categorical variables between the $\mathrm{H}_{2} \mathrm{O}_{2}{ }^{+} \leq 40 \%$ and $\mathrm{H}_{2} \mathrm{O}_{2}{ }^{+}>40 \%$ groups were investigated using the Fisher exact test or $\chi^{2}$ test where appropriate. Statistical significance was set at $P<.05$.

* No statistical analysis was performed because only 1 case was reported. 
CGD in the literature; however, it is not possible to establish a correlation.

Battersby et al [6] reported on a cohort of 81 patients, of whom $40(49 \%)$ had gastrointestinal symptoms, with the most frequent manifestations being abdominal pain and diarrhea. No definitive diagnosis was made in most cases; only 3 had a previous diagnosis of inflammatory bowel disease, and a further 3 were diagnosed during the study [6]. We found that the most frequent intestinal symptoms were chronic intermittent noninfectious diarrhea and constipation. However, endoscopic studies were not performed, and the diagnosis of inflammatory bowel disease was not confirmed.

We found 4 autoimmune diseases: rheumatoid arthritis, Sjögren syndrome, juvenile idiopathic arthritis, and hemolytic anemia. Previous studies have reported the frequency of discoid lupus to range between $8 \%$ and $40 \%$, although we only found 1 carrier with discoid lupus among the total of the participating women, possibly because of ethnicity or environmental factors.

With regard to infections, the literature has reported a higher percentage of pneumonia and skin abscesses; however, in our study, genitourinary infections were the most frequent regardless of the percentage of $\mathrm{H}_{2} \mathrm{O}_{2}{ }^{+}$neutrophils. Marciano et al [2] found a strong association between the presence of severe infections and $\mathrm{H}_{2} \mathrm{O}_{2}{ }^{+}$neutrophils $\leq 20 \%$ [2], which we did not identify, possibly because of the reduced sample size. In our series, the only carrier with $5 \% \mathrm{H}_{2} \mathrm{O}_{2}{ }^{+}$neutrophils presented with a liver abscess, recurrent genitourinary tract infections, and hidradenitis. Moreover, Rosen-Wolff et al [8] reported a 21-year-old carrier with $40 \% \mathrm{H}_{2} \mathrm{O}_{2}{ }^{+}$neutrophils. These fell to $6 \%-8 \% 23$ years later, and the patient developed pulmonary aspergillosis. Therefore, it is important to remember that the percentage of $\mathrm{H}_{2} \mathrm{O}_{2}{ }^{+}$neutrophils does not remain static in carriers, and the benefit of prophylaxis should be assessed in those with a low $\mathrm{H}_{2} \mathrm{O}_{2}{ }^{+}$neutrophil percentage.

Transient bilateral blurred vision was observed in a high percentage of patients in our cohort. Goldblatt et al [7] found a frequency of chorioretinitis of $10 \%$ in 30 female carriers. As this value could explain our findings, we recommend fundoscopy in the follow-up of XL-CGD carriers.

As for the obstetric features of XL-CGD carriers, Haidar et al [9] described the presence of recurrent chorioamnionitis in a carrier with $57 \% \mathrm{H}_{2} \mathrm{O}_{2}{ }^{+}$neutrophils. We did not find this complication in our study population; however, $33 \%$ of the carriers had had a miscarriage not related to the percentage of $\mathrm{H}_{2} \mathrm{O}_{2}{ }^{+}$neutrophils. To our knowledge, this situation has not previously been reported in XL-CGD carriers. The considerably high percentage we observed should not be ignored in the comprehensive assessment of carriers.

In addition, XL-CGD carriers benefit from antibiotic and antifungal prophylaxis, along with regular monitoring, in much the same way as patients, although the evidence is still limited [10].

Finally, our findings suggest that XL-CGD carriers have a greater risk of autoimmune and/or infectious complications than was previously thought, many of which have received little recognition by medical professionals. Most would benefit from the specific medical attention of an immunologist or internist.

\section{Funding}

This study was supported by Fundación Mexicana para Niñas y Niños con Inmunodeficiencias A.C. and CONACYT (SALUD 2012-1-180910). MA Yamazaki-Nakashimada, M Saez-de-Ocariz, SE Espinosa-Padilla, and L Blancas-Galicia have SNI-CONACYT fellowships.

\section{Conflicts of Interest}

The authors declare that they have no conflict of interest.

\section{References}

1. Battersby AC, Cale AM, Goldblatt D, Gennery AR. Clinical manifestations of disease in X-linked carriers of chronic granulomatous disease. J Clin immunol. 2013;33(8):1276-84.

2. Marciano BE, Zerbe CS, Falcone EL, Ding L, DeRavin SS, Daub $J$, et al. X-linked carriers of chronic granulomatous disease: Illness, lyonization, and stability. J Allergy Clin Immun. 2018; 141(1):365-71.

3. Cale CM, Morton L, Goldblatt D. Cutaneous and other lupuslike symptoms in carriers of $\mathrm{X}$-linked chronic granulomatous disease: incidence and autoimmune serology. Clin Exp immunol. 2007;148(1):79-84.

4. Sillevis Smitt JH, Weening RS, Krieg SR, Bos JD. Discoid lupus erythematosus-like lesions in carriers of $\mathrm{X}$-linked chronic granulomatous disease. Br J Dermatol. 1990;122(5):643-50.

5. Kragballe K, Borregaard N, Brandrup F, Koch C, Staehrjohansen $\mathrm{K}$. Relation of monocyte and neutrophil oxidative metabolism to skin and oral lesions in carriers of chronic granulomatous disease. Clin Exp Immunol. 1981;43(2):390-8.

6. Battersby AC, Braggins H, Pearce MS, Cale CM, Burns SO, Hackett $S$, et al. Inflammatory and autoimmune manifestations in X-linked carriers of chronic granulomatous disease in the United Kingdom. J Allergy Clin Immunol. 2017; 140(2):62830.

7. Goldblatt D, Butcher J, Thrasher AJ, Russell-Eggitt I. Chorioretinal lesions in patients and carriers of chronic granulomatous disease. J Pediatr. 1999;134(6):780-3.

8. Rosen-Wolff A, Soldan W, Heyne K, Bickhardt J, Gahr M, Roesler J. Increased susceptibility of a carrier of X-linked chronic granulomatous disease (CGD) to Aspergillus fumigatus infection associated with age-related skewing of lyonization. Ann Hematol. 2001;80(2):113-5.

9. Haidar ZA, Malshe A, McKenna D. Chronic granulomatous disease carrier with recurrent poor obstetric outcome. Obstet Gynecol. 2014;123(2 Pt 2 Suppl 2):484-6.

10. Roesler J. Carriers of $X$-linked chronic granulomatous disease at risk. Clin Immunol. 2009;130(2):233; author reply 4.

I Manuscript received July 19, 2018; accepted for publication October 18, 2018

Lizbeth Blancas-Galicia blancas.lizbeth@gmail.com 